УДК 655.3.022

๑ О. І. Кушлик-Дивульська, к.Ф.-М.н., доцент, Б. Р. Кушлик, К.т.н., асистент, НТУУ «КПІ», Київ, Україна

\title{
МАТЕМАТИЧНА ТЕОРІЯ ОПТИМАЛЬНОГО КЕРУВАННЯ В ПРАКТИЧНИХ ЗАДАЧАХ
}

В статті здійснено аналіз літератури, наведено приклади задач оптимального керування в різноманітних сферах людської діяльності. Також проаналізовано деякі задачі оптимального керування в поліграфічній галузі, зокрема, задачу оптимального керування з запізненням в механічних рухах поліграфічного друкарського обладнання.

Ключові слова: технологічний процес; оптимальне керування; допустиме керування; задача синтезу; запізнення; принцип максимуму.

\section{Постановка проблеми}

3 моменту своєї появи принцип максимуму привертає увагу багатьох спеціалістів. Справа в тому, що з кожним роком питома вага задач, пов'язаних з вибором оптимальних конструкцій, режимів і т. п., швидко зростає в різних сферах людської діяльності. Деякі із цих задач відомі давно, але через свою складність були недоступні для ефективного розв'язку. За короткий проміжок часу в цій області виконано ряд робіт і покладено початок новим потужним методам дослідження. Для лінійних систем принцип максимуму було доведено Р. В. Гамкрелідзе (1957р.), який також побудував повну теорію таких лінійних керованих об'єктів. Ці дослідження послужили основою для гіпотези Л. С. Понтрягіна про справедливість принципу максимуму в загальному випадку. В ряді випадків задача оптимального керування ус- кладнюється ефектом запізнення, яке може виникати у зв'язку із затратою часу на передачу сигналу або, як це часто буває, дія проміжних і підсилюваних ланок у керованому об'єкті зводиться до передачі сигналу із запізненням. Майже одразу ж принцип максимуму був поширений Г. Л. Харатишвілі (1961 р.) на системи рівнянь із запізненням. Тому є цікавими дослідження в поліграфічній галузі стосовно цього принципу, тобто побудова математичних моделей оптимізаційних задач, власне, моделей реальних об'єктів із запізненням, які використовуються у поліграфічній галузі.

\section{Аналіз попередніх} досліджень

Принципом максимуму називають математичний метод, який розробив академік Л. С. Понтрягін зі своїми учнями для розв'язання задач оптимального керування. Запропонована авторами 


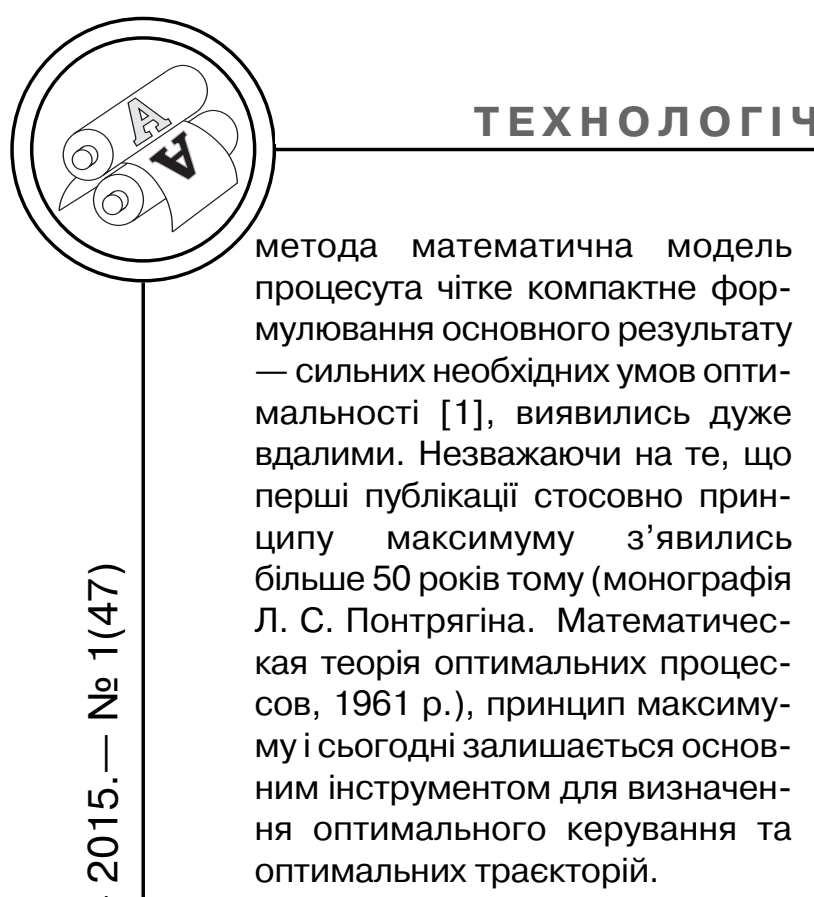

Основні навчальні задачі оптимального керування

Максимізація дії польоту апарата в атмосфері. Для літального апарата, положення якого задається відстанню та висотою польоту, величиною та кутом нахилу до горизонту вектора швидкості керуваннями вважають кут та функцію, яка дає можливість змінювати геометрію кривої в польоті. Потрібно знайти такі оптимальні функції, для яких досягається максимум відстані польоту.

Задача про оптимальну витрату палива під час руху ракети у вакуумі. Для керованого ракетного апарата в тривимірному просторі (стан його описується вектором швидкості та значенням маси) потрібно вибрати так напрям його руху, щоб у фіксований момент часу досягти задану точку із вказаною швидкістю та мінімізувавши витати палива.

Оптимальний розподіл ресурсів. Деяка початкова сума грошей витрачається на придбання обладнання двох типів А та В. Розподіляючи наявний дохід між різними типами обладнання, до кінця строку експлуатації одержують певний економічний ефект. Потім амортизоване обладнання реалізують, і одержану виручку знову використовують як початкову суму для наступного циклу і т. д. Потрібно знайти таку стратегію розподілу коштів для закупки обладнання двох типів А та В у кожному циклі, щоб забезпечити найбільший економічний ефект після фіксованого числа виробничо-економічних циклів.

Розподіл температури в тонкому стержні скінченної довжини із теплоізольованими кінцями. Стан об'єкта описується функцією розподілу температури вздовж стержня, яка залежить від часу. Задача полягає в відшуканні такого керування, тобто густини теплових джерел, для якого розподіл температури досягне якомога швидше заданого стану.

Задача оптимального розподілу капіталовкладень в галузі на заданому проміжку планування. Стан галузі характеризується величиною основних виробничих фондів, кількість яких зростає за рахунок капіталовкладень та зменшується через фізичне та моральне зношення. Капітальні вкладення в галузь вважають керуваннями, а критерій оптимальності процесів водночас враховує економію капіталовкладень, з однієї сторони, і збільшення основних виробничих фондів галузі, - $з$ іншої. Цю задачу також узагальнюють на випадок декількох галузей. Тоді розподіл капіталовкладень потрібно забезпечити не тільки в часі, а між галузями також. 
Практичні задачі в поліграфічній галузі

Поліграфія однією з перших серед галузей виробництва стала застосовувати комп'ютерну техніку спочатку у видавничих, а згодом у друкарських і післядрукарських процесах, 3 метою скорочення часу випуску друкованих видань, адекватного реагування на постійне збільшення номенклатури видань та зменшення їх накладів.

Друкарні, які друкують такий вид поліграфічної продукції, як роздавальний матеріал, візитівки, бірдекелі, стікери, промоматеріал, тощо, отримують замовлення на друк цих видів поліграфічної продукції від різних клієнтів, як правило невеликим накладом. Для зменшення собівартості друку та збільшення прибутку друкарні доцільно поєднувати замовлення від різних клієнтів у спільну роботу. Вирішення задачі поєднання замовлень у один друкарський аркуш також дозволяє економити витратні матеріали, що у свою чергу сприяє зменшенню екологічного забруднення навколишнього середовища.

У роботі [2] пропонується математична модель оптимізаційної задачі знаходження оптимального формату друкованого аркуша для розміщення заданої множини поліграфічних об'єктів - спільна робота, яка об'єднує в собі замовлення на друк від різних клієнтів. Запропоновані об'єкти $€$ моделями реальних об'єктів, які використовуються у поліграфічній галузі. В роботі запропоновано метод розв'язання поставленої задачі та, відповідно, розробле- на програмна реалізація моделювання оптимального розміщення складених phi-об'єктів, форма яких $є$ прямокутником із заокругленими кутами, які використовуються у поліграфічній галузі. Наводяться результати обчислювальних експериментів.

Сьогодні актуальною стає науково-технічна проблема системного аналізу та синтезу топологій комп'ютерних видавничо-поліграфічних систем та створення обчислювальних методів опрацювання матричних моделей топологій для побудови ефективних програмних засобів проектування таких систем [3].

Розроблені автором [3] методи аналізу та синтезу топологій комп'ютерних видавничополіграфічних систем забезпечують ефективне виявлення та перетворення топологічних структур, визначення часу i блоків, що утворюють критичні та мінімальні шляхи, а також «вузьких» місць таких структур. Вони базуються на застосуванні матриць суміжностей як математичних моделей, що забезпечує просту їх реалізацію на рівні мов програмування. Розроблені методи аналізу та синтезу розв'язують ширше коло задач, зокрема при проектуванні апаратного забезпечення спеціалізованих комп'ютерних систем, комп'ютеризованих технологічних ліній.

Практична цінність полягає в тому, що на отриманій новій теоретичній основі розроблена система автоматизованого проектування поліграфічних систем, яку використано в Українській академії друкарства 


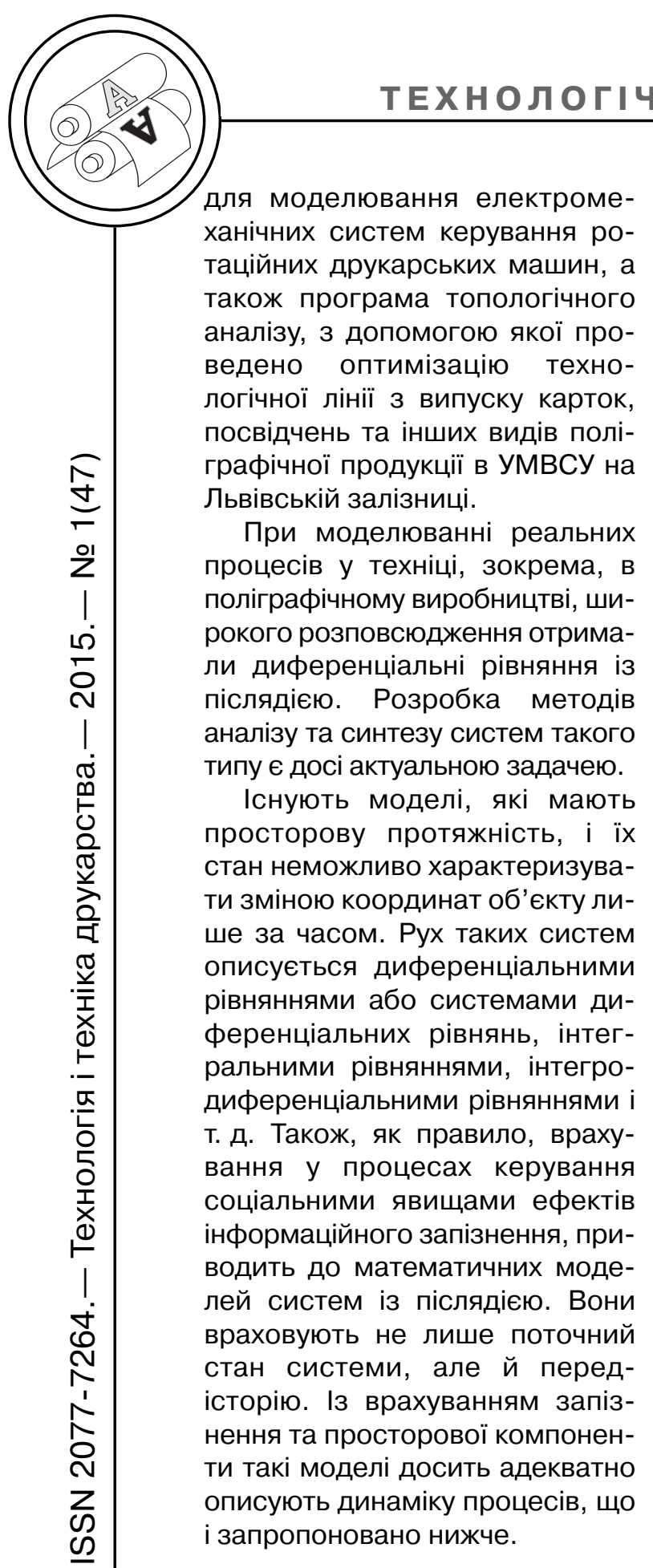

\section{Мета роботи}

Застосування принципу максимуму Понтрягіна для побудови оптимальних траєкторій подавання фарби (зволожувального розчину) від початкової точки до друкарської форми із врахуванням проходження умовною точкою складної системи валів, що здійснюють обертові, коливні та обертовоколивні рухи.

\section{Результати проведених досліджень}

Важливою $є$ задача пошуку оптимального керування, яка певним чином дасть змогу змоделювати необхідні переміщення у подачі фарби та зволожувального розчину на друкувальний елемент.

В роботі [4] досліджена математична модель синтезу лінійного полімеру з врахуванням зворотності і спонтанної термінації (стоку) реакцій синтезу. Автором доведено, що за умови більшої швидкості прямого процесу від зворотного, динаміка напрацювання кінцевої речовини при нескінченному зростанні числа проміжних стадій та збереженні загального часу прямого та зворотного процесів записується розв'язком відповідного рівняння із запізнюючим аргументом.

Розглянемо типовий фарбовий та зволожувальний апарат друкарської машини плоского офсетного друку. Очевидно, що при зміні подавання фарби чи зволожувального розчину із початкової до кінцевої точки, тобто до друкарської форми, зміна прийде не одразу, а з певним запізненням. Запізнення, що виникають в системах, де на якусь відстань передається енергія, речовина, сигнал і т. п. називаються транспортними і зустрічаються у багатьох технологічних процесах. 
При цьому умовна точка із новою кількістю чи то фарби, чи то зволожувального розчину, проходитиме через складну систему валів, що здійснюють обертові (розкочувально-накочувальна група), коливні (передавальний валик) та обретовоколивні (осцилюючі валики розкочувальної групи) рухи.

Рух певної точки вказаних вище валів фарбового апарата друкарської машини описується системою лінійних диференційних рівнянь з запізненням:

$$
\left\{\begin{array}{l}
\frac{d x_{1}(t)}{d t}=x_{2}(t) \\
\frac{d x_{2}(t)}{d t}=-x_{1}(t-\Delta)+U(t)
\end{array}\right.
$$

де кусково-неперервне $U(\mathrm{t})$ обмежене за абсолютною величиною $|\mathrm{U}(\mathrm{t}) \leq 1|$, запізнення $\Delta$ стале: $\Delta=$ const і виконується початкова умова:

$$
\mathrm{x}_{1}(\mathrm{t})=0 \text { при } \mathrm{t} \in[-\Delta ; 0]
$$

Стандартною задачею керування вважається задача найшвидшого переведення керованої точки з початкового стану (0; a) в наперед задану точку (b; c), причому без обмеження загальності припускається а >0, b >0, c >0. Проте для реальних поліграфічних процесів задачу керування необхідно розглядати з деякими обмеженнями, які зумовлюються певними технологічними умовами друку. Зокрема, обмеження можуть бути як фазового характеру, так і енергетичних чи сировинних витрат.

Розглянуто фазове обмеження як умову існування моменту часу $t_{1}>0$, при якому ще до до- сягнення точки (b, c) виконується нерівність:

$$
x_{2}\left(t_{1}\right) \leq 0 .
$$

Задача синтезу оптимальних керувань для системи (1) з умовами (2) та (3) розв'язується за допомогою побудови відповідного до системи (1) гамільтоніану

$$
\begin{gathered}
H=\Psi_{1}(\mathrm{t}) \cdot \mathrm{x}_{2}(\mathrm{t})-\Psi_{2}(\mathrm{t}) \cdot \\
\cdot\left(\mathrm{x}_{1}(\mathrm{t}-\Delta)-\mathrm{U}(\mathrm{t})\right)
\end{gathered}
$$

та дослідження відповідної для нього системи рівнянь з випередженням. Дана задача задовольняє необхідні умови оптимальності за швидкодією, за якою для допустимого керування та відповідного йому траєкторії руху 3 початковою функцією існують ненульові функції $\Psi_{1}(\mathrm{t}), \Psi_{2}(\mathrm{t})$, відповідні $\mathrm{x}(\mathrm{t}), \mathrm{u}(\mathrm{t})$, що на них досягається максимум.

Побудовано гамільтоніан (4) вигляду

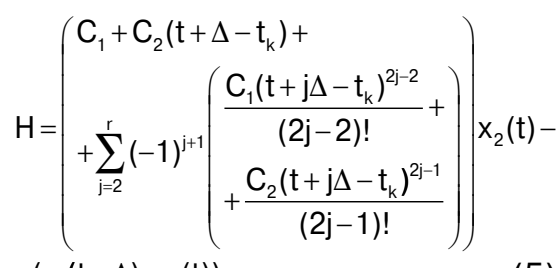

$-\left(x_{1}(t-\Delta)-u(t)\right)$.

$\cdot\left(C_{2}+\sum_{j=1}^{r}(-1)^{j}\left(\begin{array}{l}\frac{C_{1}\left(t+j \Delta-t_{k}\right)^{2 j-1}}{(2 j-1) !}+ \\ +\frac{C_{2}\left(t+j \Delta-t_{k}\right)^{2 j}}{(2 j) !}\end{array}\right)\right)$,

якщо $t_{k}-(r+1) \Delta<t \leq t_{k}-r \Delta$, та $r=1,2,3, \ldots$

На останньому часовому проміжку $\mathrm{t}_{\mathrm{k}}-\Delta<\mathrm{t} \leq \mathrm{t}_{\mathrm{k}}$ гамільтоніан з урахуванням розв'язку системи 


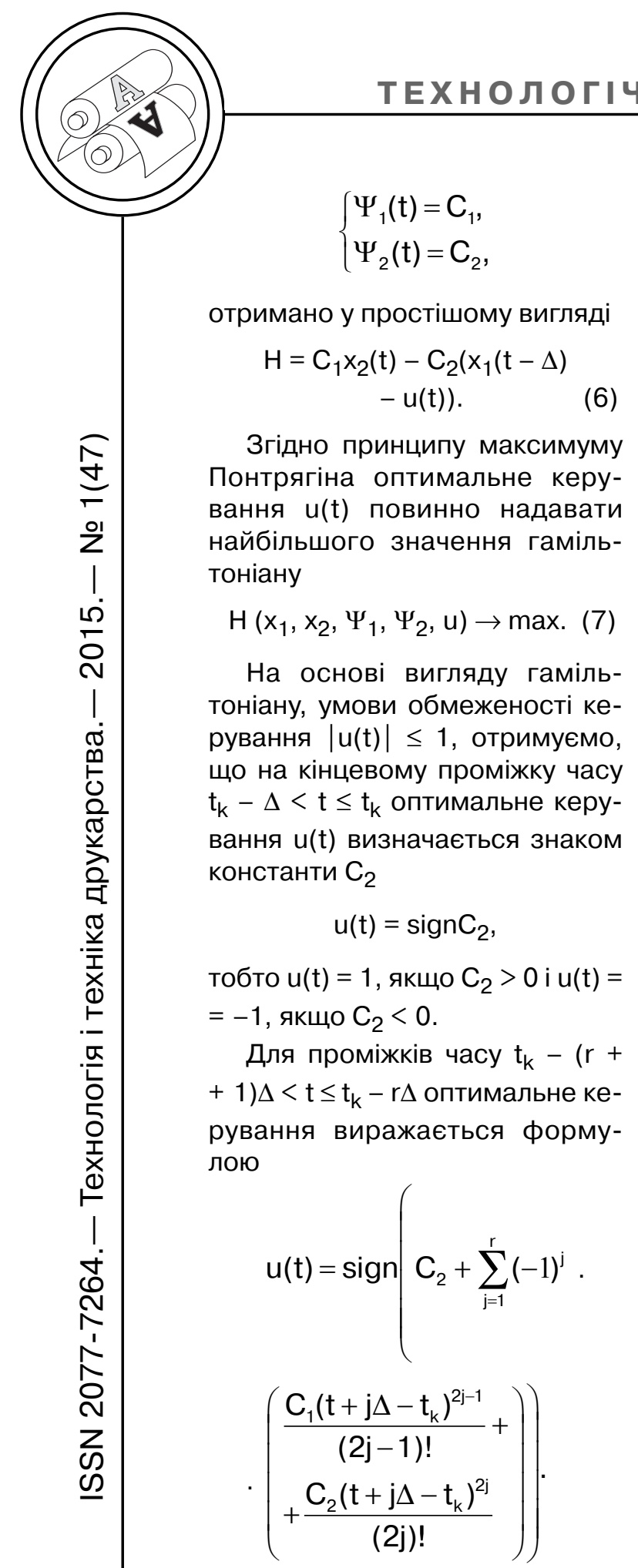

Якщо $\mathrm{u}=1$, то система рівнянь (1)набуває вигляду

$$
\left\{\begin{array}{l}
\frac{d x_{1}(t)}{d t}=x_{2}(t) \\
\frac{d x_{2}(t)}{d t}=-x_{1}(t-\Delta)+1
\end{array}\right.
$$

Шуканий розв'язок системи (1) при $0<\mathrm{t} \leq \Delta$ визначається функціями:

$$
\left\{\begin{array}{l}
x_{1}(t)=\frac{1}{2} t^{2}+a t \\
x_{2}(t)=t+a
\end{array}\right.
$$

із якої отримаємо цю траєкторію в явному аналітичному вигляді

$$
x_{1}=\frac{1}{2} x_{2}^{2}-\frac{a^{2}}{2}
$$

Отже, траєкторією руху від початкового моменту часу $t=0$ до моменту часу, рівного за величиною запізнення $\mathrm{t}=\Delta, \epsilon$ частина квадратичної параболи. Якщо задана точка (b, c) належить вказаній лінії при $а \leq \mathrm{x}_{2} \leq$ $\leq \mathrm{a}+\Delta$, то задачу керування можна вважати розв'язаною.

Отже, якщо $\mathrm{b}=\frac{1}{2} \mathrm{c}^{2}-\frac{1}{2} \mathrm{a}^{2} \quad \mathrm{i}$ $\mathrm{a}<\mathrm{c} \leq \mathrm{a}+\Delta$, то оптимальним керуванням буде стале значення $\mathrm{u}=1$, при якому завдання переміщення точки пристрою 3 початкового стану (0; а) в задану точку (b, c) буде виконане за мінімально можливий час $t_{k}$, який визначається рівністю $\mathrm{x}_{2}\left(\mathrm{t}_{\mathrm{k}}\right)=\mathrm{t}_{\mathrm{k}}+\mathrm{a}=\mathrm{c}$, звідки $\mathrm{t}_{\mathrm{k}}=\mathrm{c}-\mathrm{a}$.

Якщо ж рівність $\mathrm{b}=\frac{1}{2} \mathrm{c}^{2}-\frac{1}{2} \mathrm{a}^{2}$ виконується при с $>\mathrm{a}+\Delta$ або ця 
рівність не виконується, то задачу оптимального керування розвантажувальним пристроєм поліграфічної машини потрібно розв'язувати далі, вибравши для цього один 3 таких можливих варіантів:

а) поміняти початкове керування на протилежне за знаком, тобто замість $\mathrm{u}=1$ взяти $\mathrm{u}=-1$;

б) залишаючи початкове керування $\mathrm{u}=1$, знайти момент часу, при якому його потрібно поміняти на протилежне;

в) перейти на наступний часовий проміжок, тобто розглянути $\Delta<\mathrm{t} \leq 2 \Delta$.

Отже, траєкторію руху відповідної точки розвантажувального пристрою, можна продовжити на довільний проміжок часу. Змінюючи при цьому у відповідні моменти часу керування и $3+1$ на -1 і навпаки, цією точкою можна досягти будь-яке наперед задане місцезнаходження у фазовій площині. При цьому керування буде оптимальним за швидкодією у випадку, коли моменти часу, в які знак керування змінюється, будуть однократними коренями функцій $\Psi_{2}(\mathrm{t})$.

Проведене дослідження показує існування можливості налаштування процесу досягнення та постійного підтримання балансу «фарба-вода», маючи певні значення та величини подачі фарби, зволожувального розчину, відповідно до кількості друкувальних та пробільних елементів на друкарській формі.

\section{Висновки}

Запропонована математична модель рішення задачі пошуку оптимальних керувань при виборі та корегуванні величини подачі фарби і зволожувального розчину у процесі налаштування друкарської машини до друку та при підтриманні унормованих значень оптичної густини та колірних відмінностей на відбитку у процесі друку з дотриманням балансу «фарбавода», в якому визначено траєкторію зміни кількості фарби чи зволожувального розчину при керуванні «збільшення» чи «зменшення».

\section{Список використаної літератури}

1. Понтрягин Л. С. Математическая теория оптимальных процессов / Л. С. Понтрягин, В. Г. Болтянский, Р. В. Гамкрелидзе, Е. Ф. Мищенко. - М. : Наука, 1969. - 384 с.

2. Гребеннік І. В. Математичне моделювання відношень геометричних об'єктів в задачах оптимального розміщення в поліграфії / І. В. Гребеннік, Д. В. Грицай, Т. Є. Романова // Тези доповідей Всеукраїнської науковопрактичної конференції «Проблеми інформатики та комп'ютерної техніки». - Чернівці : Видавничий дім «Родовід», 2013. - 166 с.

3. Дунець Р. Б. Математичні моделі та методи аналізу й синтезу топологій комп'ютерних видавничо-поліграфічних систем : дис... д-ра техн. наук : 01.05.02 / Українська академія друкарства. - Л., 2004. 370 арк. - Бібліогр. : арк. 248?269.

4. Лихошвай В. А. Моделирование уравнением с запаздывающим аргументом многостадийного синтеза без ветвления / В. А. Лихошвай, С. И. Фадеев, Г. В. Демиденко, Ю. Г. Матушкин // Сиб. журн. индустр. математики. 2004. - Том VII. - № 1(17). - С. 73-94. 


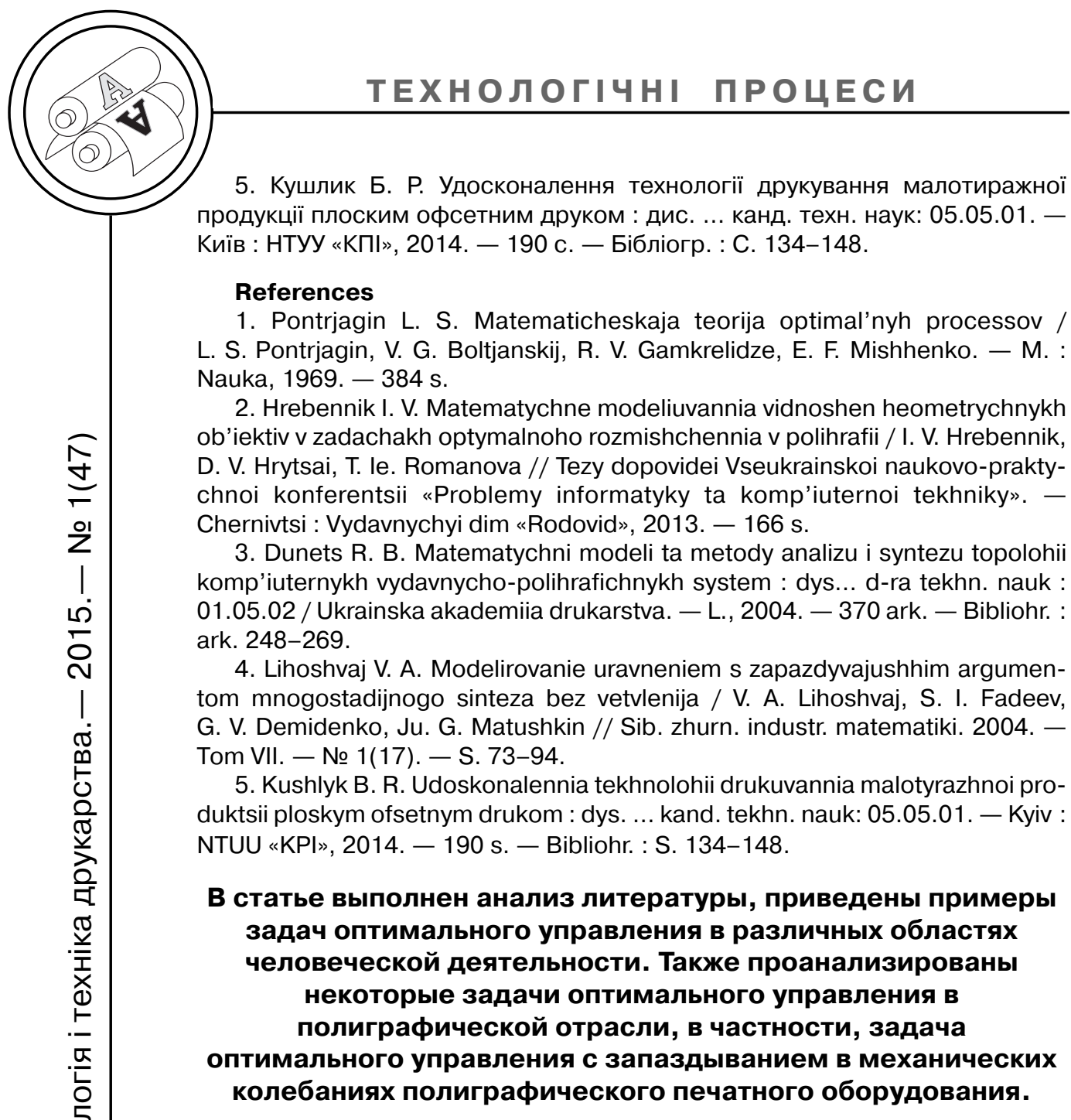
Ключевые слова: технологический процесс; оптимальное управление; допустимое управление; задача синтеза; запаздывание; принцип максимума.

In this article the literature analysis is provided, also the examples of tasks for optimal control in different fields are described. Some aspects of optimal control tasks in the printing industry are analyzed. The detailed task of optimal control with the delay in mechanical moves of the printing equipment is deeply analyzed.

Keywords: technological process; optimal control; acceptable
control; the synthesis task; delay; maximum principle. Рецензент - О. В. Зоренко, к.Т.н., доцент, НТУУ «КПI»

Надійшла до редакції 13.03.15 